\title{
Long-term survival after the Fontan operation: Twenty years of experience at a single center
}

\author{
Tacy E. Downing, MD, ${ }^{\mathrm{a}}$ Kiona Y. Allen, MD, ${ }^{\mathrm{a}}$ Andrew C. Glatz, MD, MSCE, ${ }^{\mathrm{a}}$ Lindsay S. Rogers, MD,
} Chitra Ravishankar, MD, ${ }^{\mathrm{a}}$ Jack Rychik, MD, ${ }^{\mathrm{a}}$ Jennifer A. Faerber, PhD, ${ }^{\mathrm{b}}$ Stephanie Fuller, MD, ${ }^{\mathrm{c}}$ Lisa M. Montenegro, MD, ${ }^{d}$ James M. Steven, MD,${ }^{d}$ Thomas L. Spray, MD, ${ }^{c}$ Susan C. Nicolson, MD, ${ }^{d}$ J. William Gaynor, MD, ${ }^{c}$ and David J. Goldberg, $\mathrm{MD}^{\mathrm{a}}$

\section{ABSTRACT}

Objective: Existing studies of patients palliated with the Fontan operation are limited by heterogeneous patient populations and incomplete follow-up. This study aimed to describe long-term post-Fontan survival in a modern patient cohort.

Methods: All 773 patients who underwent a first Fontan operation at our institution between 1992 and 2009 were reviewed. The primary outcome was the composite endpoint of Fontan takedown, heart transplantation, or death before 2013.

Results: Follow-up rate was $99.2 \%$. Survival with intact Fontan circulation was $94 \%$ at 1 year ( $95 \%$ confidence interval [95\% CI], 92\%-95\%), $90 \%$ at 10 years (95\% CI, $88 \%-92 \%), 85 \%$ at 15 years $(95 \%$ CI, $82 \%-88 \%)$, and $74 \%$ at 20 years $(95 \%$ CI, 67\%-80\%). Distinct risk factors were identified for early $(\leq 1$ year) and late composite outcomes. Independent risk factors for early outcome included prolonged pleural drainage (hazard ratio [HR], 4.4; $P<.001$ ), intensive care unit stay $>1$ week (HR, 2.4; $P<.001$ ), Fontan before 1997 (HR, 3.3; $P<.001$ ), preoperative atrioventricular valve regurgitation (HR, 2.0; $P<.001$ ), and longer crossclamp time (HR, 1.3 per 10 minutes; $P<.001$ ). Late outcome was predicted by atrioventricular valve regurgitation prior to Fontan (HR, 2.0; $P \leq .001$ ), and post-Fontan ICU stay $>1$ week (HR, $2.4 ; P<.001$ ).

Conclusions: Long-term mortality after Fontan operation remains substantial. Risk factors for death or loss of Fontan circulation differ between the early and late postoperative periods. Long-term survival has not improved appreciably over the last decade, suggesting that alternatives to the Fontan are warranted. (J Thorac Cardiovasc Surg 2017;154:243-53)

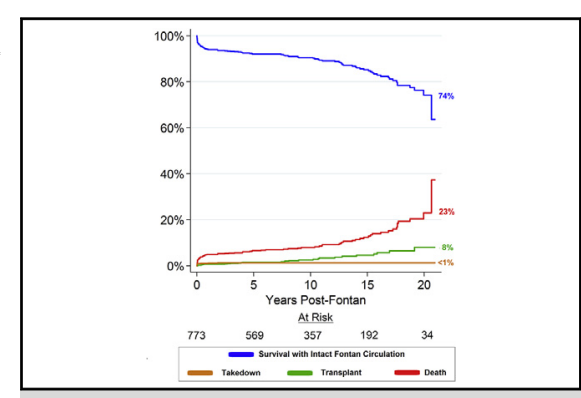

Kaplan-Meier curves showing composite and individual post-Fontan outcomes.

\section{Central Message}

Patient-specific risk factors predict post-Fontan mortality, which remains substantial in the modern single ventricle population

\section{Perspective}

This study examines post-Fontan outcomes in a modern single-ventricle population with a high prevalence of systemic right ventricles and exclusively total cavopulmonary connectiontype operations. Patient-specific risk factors predict early and late post-Fontan mortality and need for heart transplantation. Twentyyear mortality remains substantial, and alternatives to the Fontan operation are needed.

See Editorial Commentary page 254

See Editorial page 241.

\footnotetext{
From the ${ }^{\mathrm{a}}$ Division of Pediatric Cardiology, ${ }^{\mathrm{b}}$ Department of Pediatrics, ${ }^{\mathrm{c}}$ Department of Surgery, and ${ }^{\mathrm{d} D e p a r t m e n t}$ of Anesthesiology and Critical Care, The Cardiac Center at The Children's Hospital of Philadelphia, Philadelphia, Pa; and ${ }^{\mathrm{e} C i n c i n-}$ nati Children's Hospital Medical Center, Cincinnati, Ohio.

Drs Downing and Allen contributed equally to this article.

Read at the 95th Annual Meeting of The American Association for Thoracic Surgery, Seattle, Washington, April 25-29, 2015.

Received for publication April 17, 2016; revisions received Dec 21, 2016; accepted for publication Jan 15, 2017; available ahead of print March 22, 2017.

Address for reprints: David J. Goldberg, MD, The Children's Hospital of Philadelphia, 3400 Civic Center Blvd, Philadelphia, PA (E-mail: goldbergda@email. chop.edu).

$0022-5223 / \$ 36.00$

Copyright (C) 2017 by The American Association for Thoracic Surgery

http://dx.doi.org/10.1016/j.jtcvs.2017.01.056
}

In the early 1970s, Fontan and Kreutzer independently described techniques to directly reroute systemic venous return to the pulmonary arterial circulation. ${ }^{1,2}$ Although

Scanning this QR code will take you to online appendices, figure, and table. To view the AATS 2015 Webcast, see the URL next to the video thumbnail. 


$$
\begin{aligned}
& \text { Abbreviations and Acronyms } \\
& \begin{aligned}
\text { AV } & =\text { atrioventricular } \\
\text { AVVR } & =\text { atrioventricular valve regurgitation } \\
\text { CHOP } & =\text { Children's Hospital of Philadelphia } \\
\text { CI } & =\text { confidence interval } \\
\text { EC } & =\text { extracardiac conduit } \\
\text { HR } & =\text { hazard ratio } \\
\text { ICU } & =\text { intensive care unit } \\
\text { LT } & =\text { lateral tunnel } \\
\text { PA } & =\text { pulmonary artery } \\
\text { TCPC } & =\text { total cavopulmonary connection }
\end{aligned}
\end{aligned}
$$

initially designed to alleviate cyanosis in patients with tricuspid atresia, the "Fontan" operation has since been applied to the vast majority of single-ventricle anatomies as the final planned stage of surgical palliation. ${ }^{3-5}$ Subsequent modifications have improved early postoperative mortality, ${ }^{6-8}$ but significant late consequences of this inherently abnormal circulation now are being appreciated.

Long-term mortality after Fontan operation has been described in several large, single-center cohorts. $^{9-14}$ Existing studies are limited, however, by a high prevalence of older atriopulmonary style operations, few patients with hypoplastic left heart syndrome or systemic right ventricle, and/or incomplete follow up, especially regarding transplant status. In this study we aimed to describe long-term survival with intact Fontan circulation in a large cohort of modern, single-ventricle patients with a high rate of follow-up.

\section{METHODS}

This was a single-center retrospective review of all patients who underwent a first Fontan operation at The Children's Hospital of Philadelphia (CHOP) between January 1, 1992, and December 31, 2009. Fontan operation was defined as any form of total cavopulmonary connection (TCPC), including the lateral tunnel (LT) and extracardiac conduit (EC) techniques, as well as extracardiac hepatic vein inclusion conduits in patients with a previous Kawashima operation. Patients undergoing Fontan revision or repeat Fontan after previous Fontan takedown were excluded. No atriopulmonary connections were performed at $\mathrm{CHOP}$ during this time period.

Baseline demographic, anatomic, preoperative, and perioperative characteristics were extracted from the medical record as reported previously. ${ }^{15}$ Three surgical eras were defined based on relevant changes in surgical practice at our institution: 1992 to 1996 (Era 1, n = 226), 1997 to 2002 (Era 2, n = 196), and 2003 to 2009 (Era 3, n = 351). Routine use of modified ultrafiltration was introduced in 1996. In Era 1, almost all Fontan operations performed were of the LT variety, whereas in Era 3, the EC type predominated. Era 2 represented a period of transition in which the numbers of LT and EC Fontan procedures were nearly equal.

For patients currently followed at CHOP, outcomes were ascertained from the medical record. About one half $(51 \%)$ of patients had no recent follow-up at our institution. For these subjects, current vital status was obtained via a query of the National Death Index, maintained by the
National Center for Health Statistics (Atlanta, Ga). This contains a centralized database of death record information on file in United States vital statistics offices. ${ }^{16}$ At the time of data analysis, information was available through December 31, 2012. Transplant status and history of transplant listing were obtained through collaboration with the Scientific Registry of Transplant Recipients (Minneapolis, Minn). ${ }^{17}$ The primary endpoint was a composite of Fontan takedown, heart transplantation, or death before January 1, 2013. This study was approved by the institutional review board.

\section{Statistical Analysis}

Baseline demographic and clinical variables were summarized with standard descriptive statistics. Normally distributed variables were reported as mean \pm standard deviation, and non-normally distributed variables were reported as median with range. Differences across eras were assessed with analysis of variance, Kruskal-Wallis, or Pearson $\chi^{2}$ tests as appropriate. Multiple imputation based on all available demographic and clinical characteristics was used to handle the small proportion of missing data (3\% across all covariates). Kaplan-Meier survival curves were constructed to estimate overall survival and survival with intact Fontan circulation. Time zero was defined as date of Fontan, and failure was defined as Fontan takedown, heart transplantation, or death within the study period. Patients alive without takedown or transplant were censored at the end of the study period. The small minority for whom current information could not be obtained from the National Death Index or Scientific Registry of Transplant Recipients were censored at the date of last available follow-up.

Risk factors for the composite endpoint were ascertained with multivariable Cox regression. Nonproportional hazards behavior was observed for several clinically relevant predictors, so extended Cox models that incorporated a binary measure of time $(<1$ year vs $\geq 1$ year $)$ were used for these time-dependent predictors. For time-dependent variables, hazard ratios (HRs) were reported separately for the early $(<1$ year) and late $(\geq 1$ year) post-Fontan periods. Variables considered in the analysis are presented in Appendix E1. Some continuous variables were dichotomized for ease of interpretation, with cut-points chosen based on sensitivity analysis to achieve a $>90 \%$ specificity for the outcome of interest. Those with a $P$ value $<.1$ in univariable analysis and observations in at least $90 \%$ of subjects were considered for entry into the multivariable models. Variables were retained if their addition to the model generated a likelihood ratio test $P$ value $<.1$. When more than one significant multivariable model could be constructed, the model that produced the lowest Akaike information criterion score (post-test goodness-of-fit measure) was selected.

Because fewer than $90 \%$ of patients had a pre-Fontan catheterization, subset analyses were performed to examine the effects of hemodynamic parameters. These values could not be imputed because of the potential bias to refer patients with poorer physiology for catheterization at a greater rate. All $P$ values reported are 2-sided, and statistical significance was established a priori at $P \leq .05$. Analyses were conducted with STATA, v. 12.0 (StataCorp, College Station, Tex) and SAS 9.4 (SAS Institute Inc, Cary, NC).

\section{RESULTS}

A total of 773 patients underwent a first Fontan operation at CHOP between 1992 and 2009. The median number of operations performed per year was 42 (range, 26-68). Relevant demographic, preoperative, and perioperative characteristics of the study cohort are outlined in Table 1. Systemic right ventricles predominated, with $50 \%$ of patients carrying a diagnosis of hypoplastic left heart syndrome. Common atrioventricular (AV) valve was present in $11 \%$. Ninety-seven percent of patients had staged 
TABLE 1. Baseline cohort characteristics

\begin{tabular}{|c|c|c|c|c|c|c|}
\hline & $\mathbf{n}$ & Overall & 1992-1996 & 1997-2002 & 2003-2009 & $P$ value \\
\hline Total cases & 773 & $773(100 \%)$ & $226(29 \%)$ & $196(25 \%)$ & $351(46 \%)$ & \\
\hline Female & 773 & $289(37 \%)$ & $86(38 \%)$ & $66(34 \%)$ & $137(39 \%)$ & .45 \\
\hline Age at Fontan, $y$ & 773 & $2.3(0.9-38)$ & $1.7(0.9-31)$ & $2.0(1.0-29)$ & $2.8(1.3-38)$ & $<.0001$ \\
\hline Weight at Fontan, $\mathrm{kg}$ & 772 & $12.0(5.8-120)$ & $10.8(5.8-120)$ & $11.4(6.7-49)$ & $12.9(8.6-59)$ & $<.0001$ \\
\hline Heterotaxy & 773 & $66(8.5 \%)$ & $17(7.5 \%)$ & $24(12 \%)$ & $25(7.1 \%)$ & .10 \\
\hline Common AV valve & 773 & $88(11 \%)$ & $20(8.9 \%)$ & $27(14 \%)$ & $41(12 \%)$ & .28 \\
\hline Dominant RV & 763 & $524(67 \%)$ & $159(72 \%)$ & $138(73 \%)$ & $227(65 \%)$ & .11 \\
\hline HLHS & 763 & $381(50 \%)$ & $128(58 \%)$ & $99(52 \%)$ & $154(44 \%)$ & .005 \\
\hline Preoperative AVVR $\geq$ mild & 716 & $323(45 \%)$ & $78(35 \%)$ & $79(41 \%)$ & $166(56 \%)$ & $<.0001$ \\
\hline Pre-Fontan catheterization & 773 & $671(87 \%)$ & $219(97 \%)$ & $186(95 \%)$ & $266(76 \%)$ & $<.0001$ \\
\hline Mean PA pressure, $\mathrm{mm} \mathrm{Hg}$ & 627 & $11(4-25)$ & $12(4-20)$ & $10(4-20)$ & $11(5-25)$ & .05 \\
\hline Mean PA pressure $\geq 15 \mathrm{~mm} \mathrm{Hg}$ & & $75(12 \%)$ & $26(12 \%)$ & $16(9.2 \%)$ & $33(14 \%)$ & .39 \\
\hline Fontan type & 773 & & & & & $<.0001$ \\
\hline Lateral tunnel & & $409(53 \%)$ & $216(96 \%)$ & $117(60 \%)$ & $76(22 \%)$ & \\
\hline Extracardiac & & $364(47 \%)$ & $10(4 \%)$ & $79(40 \%)$ & $275(78 \%)$ & \\
\hline Fenestration & 773 & $693(90 \%)$ & $197(87 \%)$ & $179(91 \%)$ & $317(90 \%)$ & .32 \\
\hline CPB time, min & 773 & $64(32-274)$ & $59(32-147)$ & $62(41-236)$ & $66(32-274)$ & $<.0001$ \\
\hline ACC time, min & 773 & $26(0-99)$ & $27(13-93)$ & $22(0-99)$ & $27(0-91)$ & $<.0001$ \\
\hline Ventilator time & 469 & $8 \mathrm{~h}(0 \mathrm{~h}$ to $56 \mathrm{~d})$ & $20 \mathrm{~h}(1 \mathrm{~h}$ to $16 \mathrm{~d})$ & $5 \mathrm{~h}(0 \mathrm{~h}$ to $56 \mathrm{~d})$ & $5 \mathrm{~h}(0 \mathrm{~h}$ to $4 \mathrm{~d})$ & $<.0001$ \\
\hline Hospital duration, $\mathrm{d}$ & 771 & $8(0-278)$ & $13(0-278)$ & $6(2-56)$ & $8(0-108)$ & $<.0001$ \\
\hline Pleural drainage time, $\mathrm{d}$ & 745 & $3(1-258)$ & $3(1-258)$ & $1(1-40)$ & $4(1-71)$ & $<.0001$ \\
\hline Pleural drainage $>14 \mathrm{~d}$ & 745 & $126(17 \%)$ & $58(28 \%)$ & $11(6 \%)$ & $57(16 \%)$ & $<.0001$ \\
\hline
\end{tabular}

Data reported as mean \pm standard deviation, median (range), or count ( $\%$ of total). $A V$, Atrioventricular; $R V$, right ventricle; $H L H S$, hypoplastic left heart syndrome; $A V V R$, atrioventricular valve regurgitation; $P A$, pulmonary artery; $C P B$, cardiopulmonary bypass; $A C C$, aortic crossclamp.

surgical palliation, with some form of stage 2 operation preceding the Fontan. The cohort overall was divided nearly equally between LT and EC Fontan procedures, and a fenestration was created in approximately $90 \%$. A pre-Fontan cardiac catheterization for assessment of hemodynamics was performed in 671 of $773(87 \%)$ of patients, with a trend toward fewer catheterizations in the most recent era. Additional baseline characteristics and complete perioperative outcomes for the cohort have been reported previously. ${ }^{15}$

\section{Prevalence of Death, Takedown, and Heart Transplantation}

Vital status as of December 31, 2012, was ascertained for 767 of $773(99.2 \%)$ of subjects. Transplant status was verified for 764 of $774(98.7 \%)$. The median length of follow-up was 9 years post-Fontan procedure, accounting for 7616 total patient-years of follow-up. One quarter of the cohort had follow-up in excess of 15 years.

Ninety-nine $(12.9 \%)$ patients experienced at least one component of the composite outcome (Table 2). Seventy-nine patients died, 25 required heart transplantation, and 10 had Fontan takedown. Twenty-seven deaths occurred during the initial post-Fontan hospitalization and 37 during the first postoperative year. The causes of death were unable to be assessed in detail for the entire cohort because of the limitations of the data available in the National Death Index. For the patients whose cause of death was known, the vast majority were cardiac in etiology.

TABLE 2. Early and late post-Fontan outcomes by era

\begin{tabular}{|c|c|c|c|c|}
\hline & Overall $(n=773)$ & $1992-1996(n=226)$ & $1997-2002(n=196)$ & $2003-2009(n=351)$ \\
\hline \multicolumn{5}{|c|}{ Early outcomes $(<1$ y post-Fontan $)$} \\
\hline Death* & 37 & 25 & 5 & 7 \\
\hline Fontan takedown & 10 & 3 & 2 & 5 \\
\hline Transplant & 5 & 1 & 2 & 2 \\
\hline \multicolumn{5}{|c|}{ Late outcomes ( $>1$ y post-Fontan) } \\
\hline Death* & 42 & 27 & 12 & 3 \\
\hline Transplant & 20 & 14 & 4 & 2 \\
\hline \multicolumn{5}{|l|}{ All outcomes } \\
\hline Death* & 79 & 52 & 17 & 10 \\
\hline Fontan takedown & 10 & 3 & 2 & 5 \\
\hline Transplant & 25 & 15 & 6 & 4 \\
\hline
\end{tabular}

*Includes patients with previous transplant or takedown. 
All Fontan takedowns occurred within the first postoperative year, at a median of 6 days after Fontan, and all except 2 occurred during the initial post-Fontan hospitalization. One half of takedowns were performed for physiologic Fon$\tan$ failure, 1 for acute thrombosis of the Fontan circuit, 1 for endocarditis, and the indication for the remaining 3 could not be ascertained from available records.

Listing for heart transplantation occurred in 34 patients at a median age of 11 years, or 6 years after Fontan (range, 0 days to 19 years). Outcomes of transplant listing are shown in Figure E1, A. Transplantation occurred in 25 of 34 candidates $(74 \%)$. Four patients died awaiting transplantation, and 4 were removed from consideration, 2 because of clinical improvement and 2 because of clinical deterioration. One patient remains actively listed. For those successfully transplanted, the median wait time after listing was 54 days (range, 3-452). The primary indication for transplantation was ventricular dysfunction in 5 of 25 patients, Fontan failure in 8, combined Fontan and ventricular failure in 5 , and was unable to be accurately ascertained from the available records in 7 . Survival after transplant is depicted in Figure E1, $B$. Significant early mortality occurred, with an estimated survival of $50 \%$ at 5 years posttransplant.

\section{Mortality and Survival With Intact Fontan Circulation}

Survival with intact Fontan circulation was $94 \%$ at 1 year (95\% confidence interval [95\% CI], 92\%-95\%), 90\% at 10 years $(95 \% \mathrm{CI}, 88 \%-92 \%), 85 \%$ at 15 years $(95 \%$ CI, $82 \%-88 \%$ ), and $74 \%$ at 20 years $(95 \% \mathrm{CI}, 67 \%$ $80 \%$ ). Risk of transplant was $8 \%$ at 20 years, and risk of Fontan takedown was $<1 \%$ (Figure 1). In patients surviving to 1 year with intact Fontan circulation, conditional late freedom from composite outcome was $96 \%$ at 10 years (95\% CI, $94 \%-98 \%), 91 \%$ at 15 years $(95 \%$ CI, $87 \%$ $93 \%$ ), and $79 \%$ at 20 years ( $95 \%$ CI, $71 \%-85 \%$ ).

Examining mortality alone as the endpoint, survival was $95 \%$ at 1 year $(95 \% \mathrm{CI}, 93 \%-96 \%), 92 \%$ at 10 years $(95 \%$ CI, $90 \%-94 \%), 88 \%$ at 15 years (95\% CI, $85 \%-91 \%)$, and $79 \%$ at 20 years $(95 \%$ CI, $72 \%-85 \%)$. For those patients who survived the first postoperative year, conditional late survival was $97 \%$ at 10 years $(95 \%$ CI, $95 \%-98 \%)$, $93 \%$ at 15 years $(95 \% \mathrm{CI}, 90 \%-95 \%)$, and $83 \%$ at 20 years (95\% CI, 76\%-89\%).

\section{Risk Factors for Death, Transplantation, or Fontan Takedown}

Risk factors for death, transplantation, or takedown are presented in Table 3. Several covariates demonstrated statistically significant interactions with time, indicating differing effects on early and late post-Fontan outcomes. In the multivariable extended Cox model (Table 4), postoperative pleural drainage $>2$ weeks (HR, 4.4; $P<.001$ ),

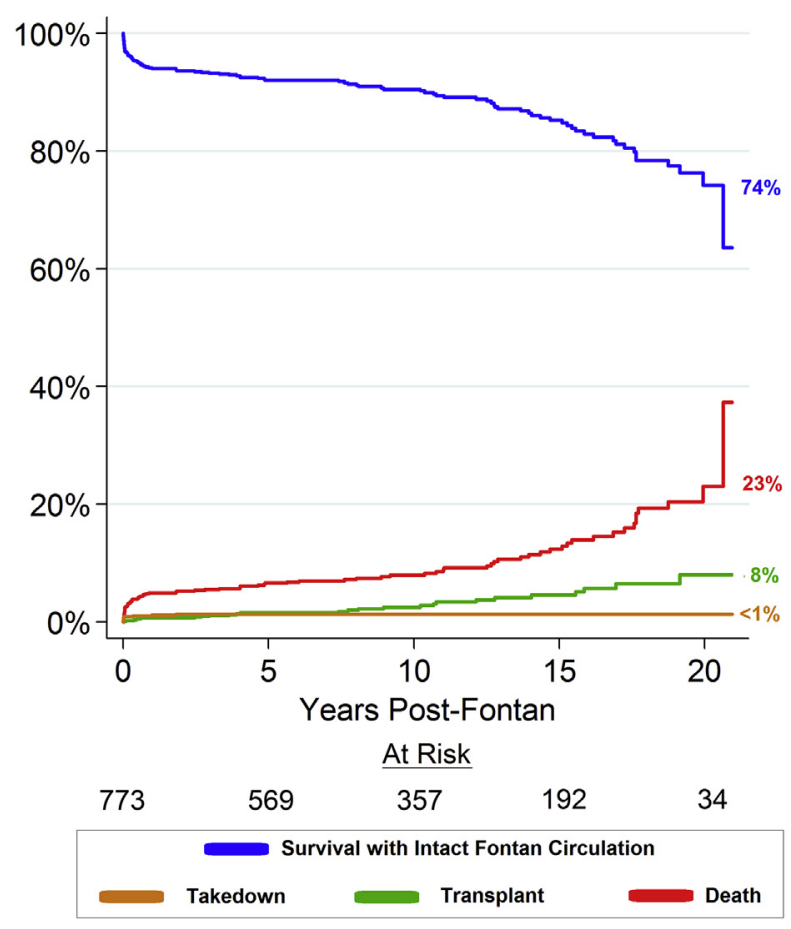

FIGURE 1. Survival and cumulative incidence of outcomes after Fontan. Kaplan-Meier survival estimate for composite outcome overlaid with cumulative hazard rates for death, transplant, and Fontan takedown. Please see Appendix E2 for $95 \%$ confidence intervals of the survival functions.

Fontan before 1997 (HR, 3.3; $P<.001$ ), intensive care unit (ICU) stay $>1$ week (HR, 2.4; $P<.001$ ), mild or greater preoperative AV valve regurgitation (HR, 2.0; $P<.001)$, and longer aortic crossclamp time (HR, 1.3 per 10 minutes; $P<.001)$ all were associated with death, transplant, or Fon$\tan$ takedown in the first postoperative year, after we adjusted for the effect of the other covariates.

The risk conferred by prolonged pleural drainage, aortic crossclamp time, and surgical era did not persist beyond 1 year post-Fontan procedure. Figure 2 demonstrates this effect with regard to surgical era, showing no impact of Fontan era on the long-term outcomes of patients who survived the first postoperative year. The only identified independent predictors of late post-Fontan mortality were mild or greater preoperative $\mathrm{AV}$ valve regurgitation and prolonged postFontan ICU stay (Figure 3). Morphology of the systemic ventricle and type of Fontan did not predict early or late failure (Figure 4). Age or weight at the time of stage 2 palliation, timing of Fontan, presence of common AV valve, and heterotaxy syndrome also did not predict adverse outcome.

In a subset analysis of the 602 patients with available catheterization-based hemodynamic data, pre-Fontan pulmonary artery (PA) pressure $>15 \mathrm{~mm} \mathrm{Hg}$ (HR, 4.1; $P<.001)$ was the strongest predictor of early composite outcome. The risk did not persist after 1 year post-Fontan, however (Table 5). 
TABLE 3. Risk factors for post-Fontan death, transplant, or takedown: Univariable analysis

\begin{tabular}{|c|c|c|c|c|c|}
\hline & \multicolumn{2}{|c|}{ Time $<1 \mathbf{y}$} & \multicolumn{2}{|c|}{ Time $\geq 1 \mathbf{y}$} & \multirow[b]{2}{*}{$P$ value for time interaction } \\
\hline & HR $(95 \%$ CI $)$ & $P$ value & HR $(95 \%$ CI $)$ & $P$ value & \\
\hline Pleural drainage $>14 \mathrm{~d}$ & $7.1(3.9-12)$ & $<.001$ & $0.9(0.4-1.8)$ & 68 & $<.001$ \\
\hline ICU stay $>1 \mathrm{wk}$ & $3.7(2.4-5.7)$ & $<.001$ & $3.7(2.4-5.7)$ & $<.001$ & .15 \\
\hline Fontan before 1997 & $3.3(1.9-6.0)$ & $<.001$ & $1.2(0.6-2.3)$ & .66 & .02 \\
\hline Lateral tunnel Fontan & $2.5(0.9-6.5)$ & .42 & $1.9(1.0-3.5)$ & .04 & .05 \\
\hline Lack of fenestration & $1.5(0.8-2.6)$ & .18 & $1.5(0.8-2.6)$ & .18 & .40 \\
\hline Common AV valve & $2.1(1.3-3.6)$ & .004 & $2.1(1.3-3.6)$ & .004 & .65 \\
\hline Systemic RV & $1.9(1.1-3.1)$ & .01 & $1.9(1.1-3.1)$ & .01 & .65 \\
\hline HLHS & $1.4(0.9-2.1)$ & .10 & $1.4(0.9-2.1)$ & .10 & .49 \\
\hline Preoperative AVVR $\geq$ mild & $2.0(1.3-3.0)$ & $<.001$ & $2.0(1.3-3.0)$ & $<.001$ & .19 \\
\hline Aortic crossclamp time, per $10 \mathrm{~min}$ & $1.1(0.9-1.3)$ & .21 & $1.4(1.2-1.6)$ & $<.001$ & .08 \\
\hline Weight at Fontan, kg & $1.04(1.01-1.06)$ & $<.001$ & $1.0(0.9-1.03)$ & .53 & .06 \\
\hline
\end{tabular}

Not significant: age at Fontan, sex, heterotaxy syndrome, Norwood operation as initial palliation. $H R$, Hazard ratio; $C I$, confidence interval; $I C U$, intensive care unit; $A V$, atrioventricular; $R V$, right ventricle; $H L H S$, hypoplastic left heart syndrome; $A V V R$, atrioventricular valve regurgitation. *Extended Cox modeling with time interaction variable. Significant $P$ value indicates covariates with differing effects in early versus late post-Fontan time periods.

\section{DISCUSSION}

In this study, we present long-term follow up of 773 consecutive patients who underwent a first Fontan operation at our institution during an 18-year period. With a $99 \%$ follow-up rate, the 20-year estimate for survival with intact Fontan circulation was $74 \%$. When we examined mortality alone, 20-year survival was 79\%. Independent risk factors for death or loss of Fontan circulation were identified, but several of these characteristics conferred risk only in the early post-Fontan period. Prolonged pleural drainage and elevated PA pressure preFontan were the strongest risk factors for early composite outcome, and late outcome was predicted only by presence of AV valve regurgitation pre-Fontan and length of postFontan ICU stay. Ventricular morphology and type of Fontan operation were not associated with early or late outcome.

The 15- and 20-year survival estimates for this cohort are within the range reported in the literature, although direct comparisons to other series are challenging because of differences in patient population and methodology. Table E1 summarizes key characteristics of selected Fontan follow-up studies from the last decade. ${ }^{9-14}$ Not surprisingly, cohorts with large numbers of atriopulmonary Fontan procedures tended to show worse long-term survival. ${ }^{11,12}$ Those with exclusively TCPC- type operations had similar survival rates to ours despite variability in surgical technique and patient selection. ${ }^{10,13}$

It does not appear that long-term survival for Fontan patients has improved substantially since the advent of the TCPC. Two studies examining Fontan operations performed in the 1980s to 1990s reported 15- and 20-year survival rates for the TCPC subgroups that were nearly identical to those seen in this study. ${ }^{11,18}$ What clearly has improved with time is early postoperative survival. Era of Fontan was identified as a risk factor for early death or loss of Fontan circulation in this cohort, a finding that has been observed in several previous studies ${ }^{10,12,13}$ and that presumably reflects advances in perioperative and ICU care. The era in which the Fontan operation was performed, however, did not have an impact on long-term survival in those patients who survived the first postoperative year.

Independent of surgical era, longer aortic crossclamp time was found to predict early failure. Duration of intraoperative support has been implicated as a risk factor previously, ${ }^{12}$ and may result in myocardial injury or serve as a marker of operative complexity (including performance of concomitant procedures). Duration of ICU stay is likewise a potential surrogate for underlying complexity and postoperative morbidity. Although it is not possible to identify the exact reasons that an individual patient in this cohort

TABLE 4. Risk factors for post-Fontan death, transplant, or takedown: Multivariable analysis

\begin{tabular}{|c|c|c|c|c|}
\hline & \multicolumn{2}{|c|}{ Time $<1 \mathbf{y}$} & \multicolumn{2}{|c|}{ Time $\geq 1 \mathbf{y}$} \\
\hline & HR $(95 \%$ CI $)$ & $P$ value & HR $(95 \%$ CI $)$ & $P$ value \\
\hline Pleural drainage $>14 \mathrm{~d}$ & $4.4(2.4-8.2)$ & $<.001$ & $0.7(0.3-1.4)$ & .31 \\
\hline Fontan before 1997 & $3.3(2.6-4.3)$ & $<.001$ & $1.1(0.6-2.3)$ & .71 \\
\hline ICU stay $>1 \mathrm{wk}$ & $2.4(1.5-3.8)$ & $<.001$ & $2.4(1.5-3.8)$ & $<.001$ \\
\hline Preoperative AVVR $\geq$ mild & $2.0(1.4-3.1)$ & $<.001$ & $2.0(1.4-3.1)$ & $<.001$ \\
\hline Aortic crossclamp time (per $10 \mathrm{~min}$ ) & $1.3(1.1-1.6)$ & $<.001$ & $1.1(0.9-1.3)$ & .48 \\
\hline
\end{tabular}

$H R$, Hazard ratio; $C I$, confidence interval; $I C U$, intensive care unit; $A V V R$, atrioventricular valve regurgitation. 

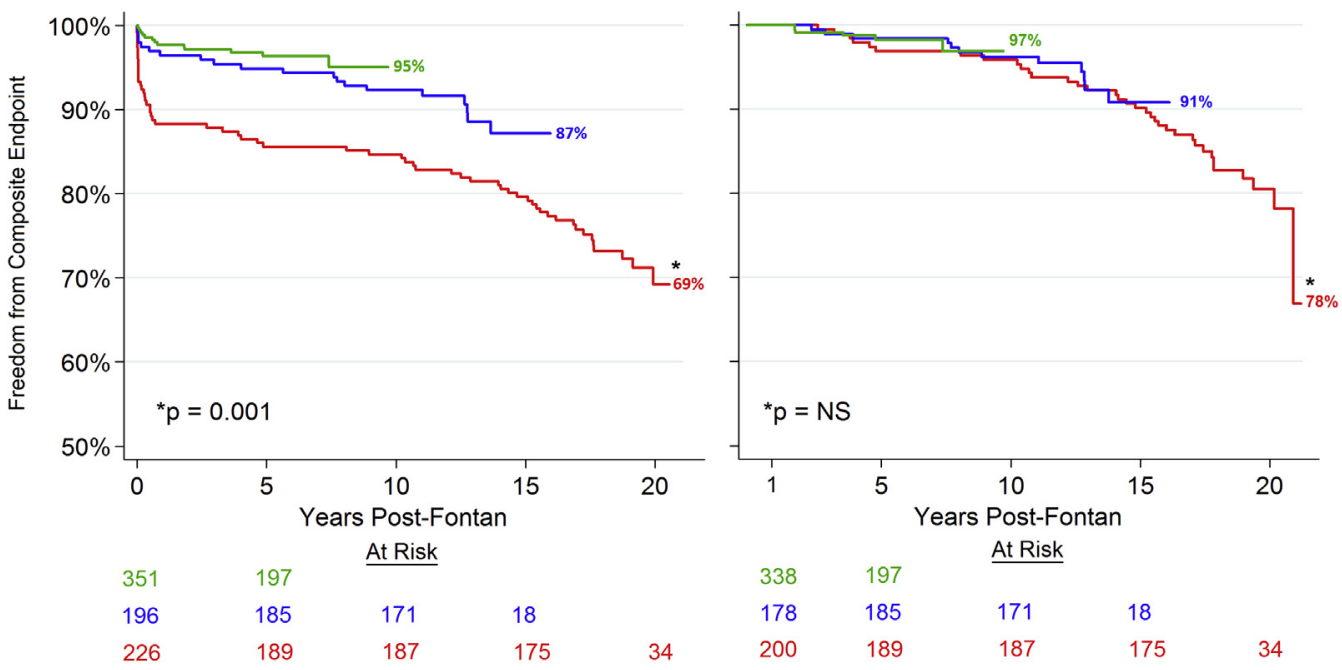

A

1992-1996 - 1997-2002 - 2003-2009

B $-1992-1996-1997-2002-2003-2009$

FIGURE 2. Impact of surgical era on transplant free survival. Kaplan-Meier survival estimate stratified by era of Fontan: (A) all patients, and (B) conditional on survival to 1 year with intact Fontan circulation. Please see supplementary Appendix E3 for 95\% confidence intervals of the survival functions.

remained in the ICU, duration of mechanical ventilation was the factor most closely correlated with duration of ICU stay in our patient cohort.

The strongest risk factor identified for early Fontan failure in the overall cohort was prolonged postoperative pleural drainage. This traditionally has been implicated as a marker of suboptimal hemodynamics, although the underlying mechanism is poorly understood and attempts to identify risk factors have produced conflicting results. ${ }^{6,19-22} \mathrm{~A}$ high burden of systemic to pulmonary arterial collaterals pre-Fontan recently has emerged as a fairly consistent predictor of prolonged effusions. ${ }^{23-25}$ Data on pre-Fontan collateral burden were not available for this cohort, but this is an area that warrants further study. Two previous Fontan follow-up studies identified prolonged pleural drainage as a risk factor for late post-Fontan death, ${ }^{9,10}$ although our study did not replicate that finding. In this cohort, duration of pleural drainage did not predict outcome in patients who survived to 1 year with intact Fontan.

In patients with available hemodynamic data, the most important predictor of early post-Fontan failure was elevated preoperative PA pressure. The number of patients referred for pre-Fontan catheterization has decreased in recent years, with a concurrent increase in noninvasive
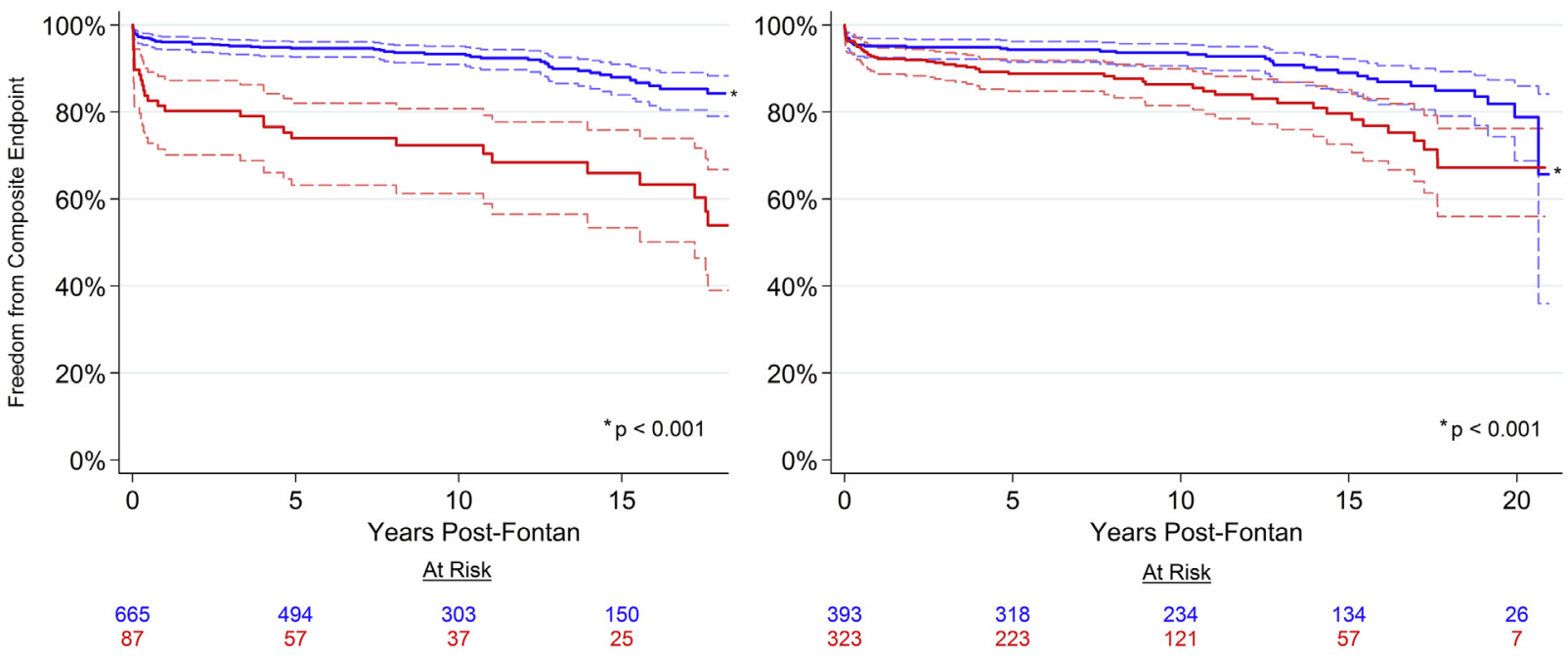

A

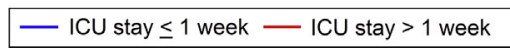

B

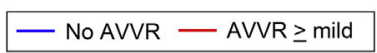

FIGURE 3. Conditional late survival stratified by duration of post-Fontan ICU stay (A) and preoperative AV valve regurgitation (B). Dashed lines represent $95 \%$ confidence intervals of the survival functions. ICU, Intensive care unit; $A V V R$, atrioventricular valve regurgitation. 

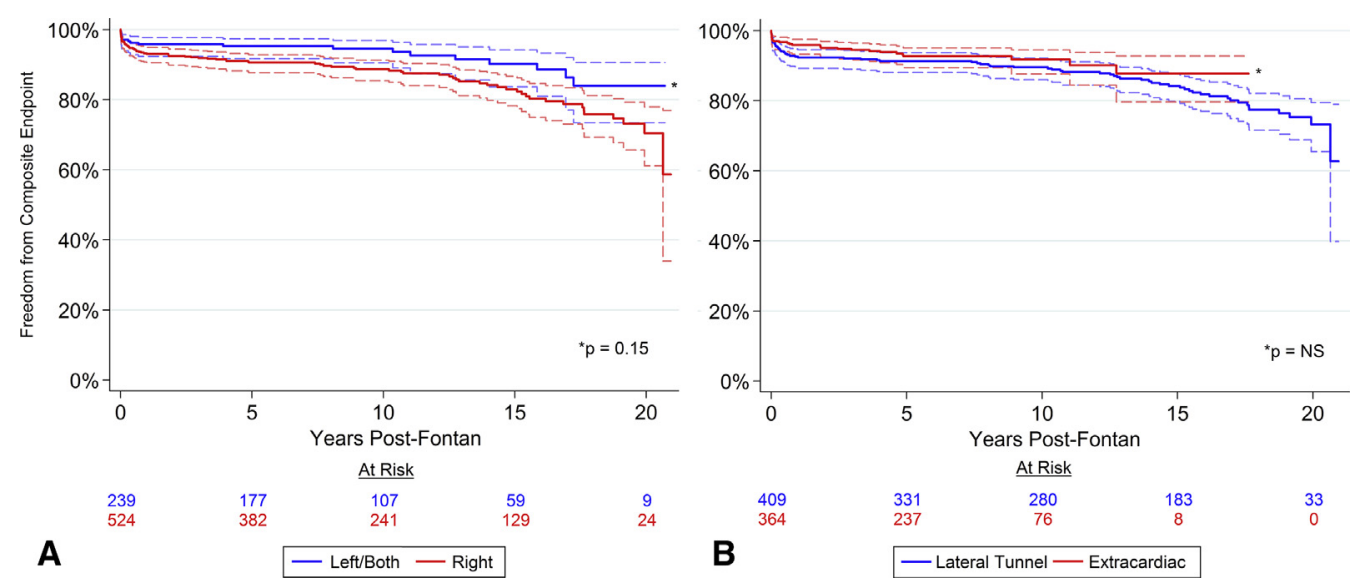

FIGURE 4. Conditional late survival stratified by (A) ventricular morphology and (B) Fontan type. Dashed lines represent $95 \%$ confidence intervals of the survival functions.

imaging methods such as cardiac magnetic resonance imaging. Although magnetic resonance imaging alone may be an appropriate strategy in low-risk patients, these findings do reinforce the potential importance of understanding not just the patient's pre-Fontan anatomy but also the physiology.

Independent risk factors for late outcome in our patients were limited to the presence of atrioventricular valve regurgitation (AVVR) before Fontan, and post-Fontan ICU stay $>1$ week. In contrast to many other studies, we defined AVVR as any degree of regurgitation more than trivial, and it persisted as a risk factor despite the fact that $50 \%$ of patients with AVVR were categorized as mild. This finding suggests that even degrees of AVVR that would not warrant surgical intervention by current indications may influence late outcomes and deserve close follow-up. The association of duration of ICU stay, an early postoperative event, with late post-Fontan outcome is interesting. This may relate at least in part to noncardiac comorbidities, which were not explicitly captured as covariates in this study.

Importantly, we demonstrated no association between long-term transplant-free survival and type of Fontan operation, presence of hypoplastic left heart syndrome, or morphology of the systemic ventricle. This cohort should be well-powered to detect those risk factors, given the equal numbers of LT and EC Fontans, and the high percentage of systemic right ventricle and hypoplastic left heart syndrome. However, although the difference in long-term transplant free survival between morphologic right and left ventricles was not statistically significant at this duration of follow-up, close examination of the Kaplan-Meier curve (Figure 4) suggests some divergence in the later post-Fontan period. It may be that a survival advantage for a systemic left ventricle is not clinically apparent until the third or fourth decade of life. The potential difference in long-term outcome between systemic left and right ventricles warrants repeat assessment in 5 to 10 years.

In the 25 patients who underwent heart transplantation, survival was $50 \%$ at just over 5 years. This finding is consistent with previous reports, ${ }^{26-28}$ although there are limited studies dedicated to transplant in the single-ventricle population. Given the relative infrequency of transplantation, multicenter studies will be required to investigate longterm outcomes in these patients.

There are several limitations to this study that should be noted. First, this was a retrospective study design, and as such there was a small percentage of missing covariate information. This did not exceed the preestablished tolerance level of $10 \%$ for any of the analyzed risk factors. Second, there is always the potential for unmeasured covariates. Our analysis suggests that the identified predictors explain only a modest portion of the observed variability in

TABLE 5. Risk factors for post-Fontan death or transplant: Multivariable analysis of subset with hemodynamic data

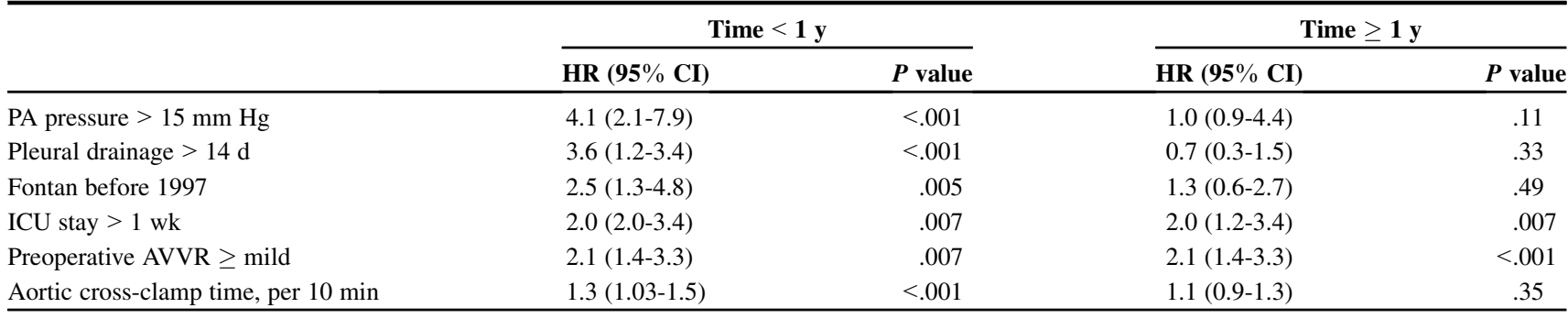

$H R$, Hazard ratio; $C I$, confidence interval; $P A$, pulmonary artery; $I C U$, intensive care unit; $A V V R$, atrioventricular valve regurgitation. 
outcomes. Finally, as with any single-center study, institutional practices influence the cohort characteristics. This study was not powered to assess the impact of Fontan fenestration, for example, because only $10 \%$ of the cohort was nonfenestrated. In addition, the current status of the fenestration is not known for many of the subjects.

\section{CONCLUSIONS}

In a large single-center cohort with a $99 \%$ follow-up rate, the 20-year estimate for survival with intact Fontan circulation is $74 \%$. Distinct risk factors were identified for early versus late mortality. Choice of EC or LT Fontan did not affect survival. Morphology of the systemic ventricle likewise did not predict outcome at this duration of followup, although longer-term observation is warranted.

Although early perioperative mortality has improved over time, late survival after Fontan surgery has not changed appreciably during the past 2 decades. Mortality or loss of Fontan circulation in nearly a quarter of patients by 20 years suggests that alternative management strategies or significant improvements to the Fontan operation are needed.

\section{Webcast}

You can watch a Webcast of this AATS meeting presentation by going to: http://webcast.aats.org/2015/Video/ Monday/04-27-15_6A_1440_Downing.mp4.

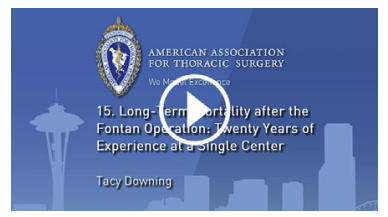

\section{Conflict of Interest Statement}

Authors have nothing to disclose with regard to commercial support.

\section{References}

1. Fontan F, Baudet E. Surgical repair of tricuspid atresia. Thorax. 1971;26:240-8.

2. Kreutzer G, Galindez E, Bono H, De Palma C, Laura JP. An operation for the correction of tricuspid atresia. J Thorac Cardiovasc Surg. 1973;66:613-21.

3. Humes RA, Feldt RH, Porter CJ, Julsrud PR, Puga FJ, Danielson GK. The modified Fontan operation for asplenia and polysplenia syndromes. J Thorac Cardiovasc Surg. 1988;96:212-8.

4. Mayer JE Jr, Helgason H, Jonas RA, Lang P, Vargas FJ, Cook N, et al. Extending the limits for modified Fontan procedures. J Thorac Cardiovasc Surg. 1986;92: 1021-8.

5. Norwood WI Jr, Jacobs ML, Murphy JD. Fontan procedure for hypoplastic left heart syndrome. Ann Thorac Surg. 1992;54:1025-9; discussion 1029-30.

6. Lemler MS, Scott WA, Leonard SR, Stromberg D, Ramaciotti C. Fenestration improves clinical outcome of the Fontan procedure: a prospective, randomized study. Circulation. 2002;105:207-12.

7. Norwood WI, Jacobs ML. Fontan's procedure in two stages. Am J Surg. 1993; 166:548-51.

8. de Leval MR, Kilner P, Gewillig M, Bull C. Total cavopulmonary connection: a logical alternative to atriopulmonary connection for complex Fontan operations. Experimental studies and early clinical experience. J Thorac Cardiovasc Surg. 1988;96:682-95.
9. d'Udekem Y, Iyengar AJ, Galati JC, Forsdick V, Weintraub RG, Wheaton GR, et al. Redefining expectations of long-term survival after the Fontan procedure: twenty-five years of follow-up from the entire population of Australia and New Zealand. Circulation. 2014;130:S32-8.

10. Hirsch JC, Goldberg C, Bove EL, Salehian S, Lee T, Ohye RG, et al. Fontan operation in the current era: a 15-year single institution experience. Ann Surg. 2008; 248:402-10.

11. Khairy P, Fernandes SM, Mayer JE Jr, Triedman JK, Walsh EP, Lock JE, et al. Long-term survival, modes of death, and predictors of mortality in patients with Fontan surgery. Circulation. 2008;117:85-92.

12. Pundi KN, Johnson JN, Dearani JA, Pundi KN, Li Z, Hinck CA, et al. 40-Year follow-up after the Fontan operation: long-term outcomes of 1,052 patients. $J$ Am Coll Cardiol. 2015;66:1700-10.

13. Dabal RJ, Kirklin JK, Kukreja M, Brown RN, Cleveland DC, Eddins MC, et al. The modern Fontan operation shows no increase in mortality out to 20 years: a new paradigm. J Thorac Cardiovasc Surg. 2014;148: 2517-23.e2511.

14. Nakano T, Kado H, Tatewaki H, Hinokiyama K, Oda S, Ushinohama H, et al. Results of extracardiac conduit total cavopulmonary connection in 500 patients. Eur J Cardiothorac Surg. 2015;48:825-32.

15. Rogers LS, Glatz AC, Ravishankar C, Spray TL, Nicolson SC, Rychik J, et al. 18 years of the Fontan operation at a single institution: results from 771 consecutive patients. J Am Coll Cardiol. 2012;60:1018-25.

16. Centers for Disease Control and Prevention. The National Death Index. Available at: https://www.cdc.gov/nchs/ndi/. Accessed June 10, 2014.

17. The Scientific Registry of Transplant Recipients. Available at: https://www.srtr. org/. Accessed April 2, 2015.

18. Ono M, Boethig D, Goerler H, Lange M, Westhoff-Bleck M, Breymann T. Clinical outcome of patients 20 years after Fontan operation - effect of fenestration on late morbidity. Eur J Cardiothorac Surg. 2006;30:923-9.

19. Cava JR, Bevandic SM, Steltzer MM, Tweddell JS. A medical strategy to reduce persistent chest tube drainage after the Fontan operation. Am J Cardiol. 2005;96: 130-3.

20. Garofalo CA, Cabreriza SE, Quinn TA, Weinberg AD, Printz BF, Hsu DT, et al. Ventricular diastolic stiffness predicts perioperative morbidity and duration of pleural effusions after the Fontan operation. Circulation. 2006; 114:I56-61.

21. Gupta A, Daggett C, Behera S, Ferraro M, Wells W, Starnes V. Risk factors for persistent pleural effusions after the extracardiac Fontan procedure. J Thorac Cardiovasc Surg. 2004;127:1664-9.

22. Mascio CE, Austin EH III. Pleural effusions following the Fontan procedure. Curr Opin Pulm Med. 2010;16:362-6.

23. Glatz AC, Rome JJ, Small AJ, Gillespie MJ, Dori Y, Harris MA, et al. Systemicto-pulmonary collateral flow, as measured by cardiac magnetic resonance imaging, is associated with acute post-Fontan clinical outcomes. Circ Cardiovasc Imaging. 2012;5:218-25.

24. Grosse-Wortmann L, Drolet C, Dragulescu A, Kotani Y, Chaturvedi R, Lee KJ, et al. Aortopulmonary collateral flow volume affects early postoperative outcome after Fontan completion: a multimodality study. J Thorac Cardiovasc Surg. 2012; 144:1329-36.

25. Odenwald T, Quail MA, Giardini A, Khambadkone S, Hughes M, Tann O, et al. Systemic to pulmonary collateral blood flow influences early outcomes following the total cavopulmonary connection. Heart. 2012;98: 934-40.

26. Alsoufi B, Deshpande S, McCracken C, Kogon B, Vincent R, Mahle W, et al. Results of heart transplantation following failed staged palliation of hypoplastic left heart syndrome and related single ventricle anomalies. Eur J Cardiothorac Surg. 2015;48:792-9.

27. Jayakumar KA, Addonizio LJ, Kichuk-Chrisant MR, Galantowicz ME, Lamour JM, Quaegebeur JM, et al. Cardiac transplantation after the Fontan or Glenn procedure. J Am Coll Cardiol. 2004;44:2065-72.

28. Michielon G, Carotti A, Pongiglione G, Cogo P, Parisi F. Orthotopic heart transplantation in patients with univentricular physiology. Curr Cardiol Rev. 2011;7: 85-91.

Key Words: congenital heart disease, cardiovascular surgery, mortality/survival, transplantation 


\section{Discussion}

Dr J. Kirklin (Birmingham, Ala). I'd first like to congratulate you on a very nice presentation and really the entire Children's Hospital of Philadelphia (CHOP) team on really spectacular long-term outcomes after the Fontan operation. You know, your results particularly are impressive, realizing that nearly one half of the patient cohort had hypoplastic left heart syndrome, making this really a unique long-term experience.

So I have 3 questions for you:

You've identified important atrioventricular (AV) valve regurgitation as a risk factor for late mortality, which was replaced by pre-Fontan pulmonary artery pressures in the multivariable analysis in the subset with pre-Fontan catheterizations. Assuming a relationship exists between $\mathrm{AV}$ valve regurgitation and these greater pre-Fontan pressures, what's your current policy regarding surgical management of $\mathrm{AV}$ valve regurgitation either prior to or at the time of the Fontan operation?

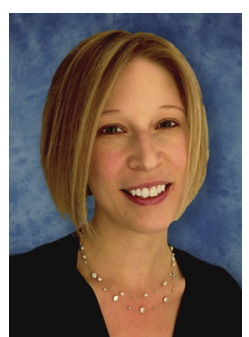

Dr Downing. Thank you very much, Dr Kirklin, for your comments. I think the question regarding $\mathrm{AV}$ valve regurgitation is a very important one and certainly one that we confront clinically on a weekly basis at our interdisciplinary surgical conference.

To clarify a little bit the relationship between pulmonary artery pressure and AV valve regurgitation in our data, you're correct in that the final multivariate model for the patients who did have a catheterization, elevated pulmonary artery pressure replaced AV valve regurgitation. The relationship is not quite so simple, however; although there was a trend toward elevated pulmonary artery pressure in patients with greater degrees of $\mathrm{AV}$ valve regurgitation, the one did not clearly predict the other-in the sense that those were not truly collinear covariates. It was simply that elevated pulmonary artery pressure is a just a better predictor, and so that entered the model whereas AV valve regurgitation, which was weaker, fell out of the model. And that being said, it's clearly important.

And to address the second part of your question as to what's our surgical strategy, we tend to try to avoid operating on the $\mathrm{AV}$ valve at the same time as doing the Fontan operation, and we really reserve that for the patients with significant degrees of AV valve regurgitation. In this cohort, there were only a total of 8 patients who had $\mathrm{AV}$ valve regurgitation that was classified as severe at the time of the Fontan, and approximately 50\% of those had an $\mathrm{AV}$ valve intervention done at the same time. There were, I think, approximately $7 \%$ to $8 \%$ who had moderate $\mathrm{AV}$ valve regurgitation, and we actually tend to leave most of those patients alone in the hope that they will improve.

Dr Kirklin. Question 2: Your outstanding experience with the Fontan operation after hypoplastic left heart syndrome is particularly instructive, but perhaps you could enlighten us on your current policy for those patients with hypoplastic left heart syndrome who do not proceed to the Fontan pathway.

Dr Downing. In terms of which patients would not be candidates for the Fontan; is that your question?

Dr Kirklin. Correct.

Dr Downing. I think for us the predisposing characteristics that would indicate that somebody is not a Fontan candidate probably are things that are not surprising to anybody here. The 2 that spring to mind are significant ventricular dysfunction or significantly elevated pulmonary artery pressure or pulmonary vascular resistance.

To address the issue of hypoplastic left heart syndrome, I think what our data have shown us is that the outcomes for those patients are not necessarily different than patients with other diagnoses that lead to the Fontan operation. And so I don't believe we have a separate set of exclusion criteria reserved specifically for patients with HLHS versus other single-ventricle diagnoses.

Dr Kirklin. And finally, I can't resist the temptation to ask you, with these really superior long-term outcomes, has this affected your calculus for decision-making in the determination of Fontan pathway versus 2-stage reconstructions for certain of the high-risk groups that perhaps have marginal indications for 2-ventricle repair?

Dr Downing. That's a difficult question to answer, and I don't think that we'll ever see a randomized trial of single-ventricle palliation versus attempt at left ventricular rehabilitation in the marginal left ventricle. And I would say that, while our survival is good, it's certainly not necessarily what somebody would hope for if you were counseling the parent of a future single-ventricle patient. If you said, "we have a great survival, there is a $25 \%$ chance that your child won't be alive in 20 years," that might not be perceived as excellent. But, I don't know that we have the data to say what that outcome would be with a biventricular approach instead. The Boston group has spoken at several national meetings this year about their experience in trying to rehabilitate the small left ventricle. What I do know is it seems like those patients have a lot of reinterventions even if you are successful, and so do the Fontan patients. I haven't presented all of the morbidity data here because we're still analyzing that, but we have a lot of reinterventions. So, I think that's a question that's still open and I don't know the definitive answer. 


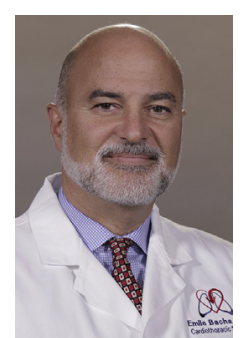

Dr E. Bacha (New York, NY). Very nice study and the follow-up in particular. It's hard to get all these patients to get an update on them, so very nice job.

My question is about the fenestration. You said that $90 \%$ of your patients were fenestrated at the initial Fontan. Can you enlighten us a little bit about the effect of that? Maybe I missed it. What data do you have?

Dr Downing. We specifically didn't really analyze the presence of fenestration as a variable in the model simply because $90 \%$ were fenestrated and so we really didn't have enough nonfenestrated patients to adequately answer that question. And also, there is a significant era effect. Almost all the nonfenestrated patients were from the early era of Fontan.

Dr Bacha. I understand. But $90 \%$ fenestration initially doesn't mean they're all patent. Most of them would not be patent. I'm talking about long-term fenestration patency.

Dr Downing. Oh, I see what you're asking. We do not have data on the current status of the fenestration on the patients.

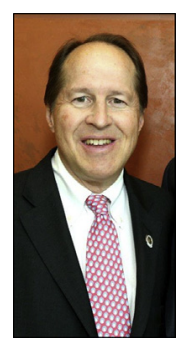

Dr Backer (Chicago, Ill). And do you actively close them or not close them? Dr Downing. It is our institutional preference generally not to close them unless there is a clear provocation or reason to do so- the patient has had a stroke, we close them-but we do not have a policy of going back at $\mathrm{X}$ so many years and just routinely closing the fenestration.

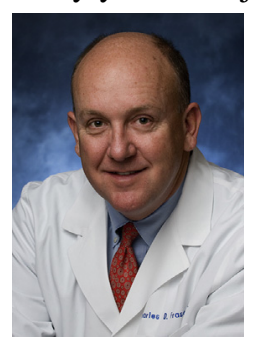

Dr C. Fraser (Houston, Tex). I first want to say this was a very elegantly presented talk. The slides were clear, readable, and you're to be congratulated. It's a real model for oral presentation, so I thank you very much.

I wanted to make sure I understood the methodology. You linked your CHOP Fontan database with the National Death Index; is that correct?

Dr Downing. That's correct.

Dr Fraser. So you had 99\% vital statistics on all these patients?

Dr Downing. That's correct. The only patients for whom we were unable to obtain current vital status were those who are currently living outside of the United States and would not be covered by the National Death Index (NDI).

Dr Fraser. I have to claim ignorance about how to use the NDI. How does one obtain informed consent from a family when you're going to link an existing database and a national index, how do you do that?
Dr Downing. The retrospective chart review portion of the study was granted a waiver of informed consent by the CHOP institutional review board.

Dr Fraser. Initially?

Dr Downing. Yes. And included in that was the query of the NDI. But the National Death Index, you have to understand, is public record. So the deaths and death dates and death certificates are a matter of public record and the NDI is simply a centralized database, a way to access it.

Dr Fraser. But it's organized by social security number, right?

Dr Downing. It was previously housed under the Social Security Administration and now it is with the National Center for Health Statistics, yes.

Dr Fraser. Well, it's an incredible tool. I think we could all learn how to use it better, because so many of our studies that we claim long-term follow-up, we have huge percentages of our patients that are lost. So this is a real opportunity as I see it.

So the question, so $20 \%$ mortality at 20 years roughly; is that right?

Dr Downing. Yes.

Dr Fraser. Your mean age at Fontan completion is 2.3 years. I've always pondered why you need to go forward with a Fontan operation at age 2 years. So, another speculation: based on this information, might you push out the age of Fontan completion as another potential conclusion from this, speculating that human beings can't live with hepatic venous pressure of 12 or $15 \mathrm{~mm}$ $\mathrm{Hg}$ for a normal lifespan?

Dr Downing. It could. I mean it's certainly a reasonable speculation to say if we can get $75 \%$ survival 20 years out why not do the Fontan operation at 7 and then they'll be a little older. But I guess one of my biases, one of the things that I spend some of my time doing is taking care of adults with congenital heart disease, and while it might be very nice to move the target from 20 years to 27 years, what about 60 and 70? And so while you might say that that could buy you an extra 5 years, I might think a little bigger and say what's going to buy us an extra 50 years. And I don't have the answer to that. I don't think it's the Fontan.

Dr G. Sarris (Athens, Greece). I'd like to congratulate you for a very nice paper and fantastic results. This is really a landmark paper.

Would you be able to tell us a little bit about your anticoagulation strategy and whether this has impacted on the results in any way and, also, if you have studied the modes of Fontan failure and the causes of death in this particular paper. 
Dr Downing. We're getting a lot of excellent questions on the non-mortality and morbidity aspects of the data, and I'll qualify my answers by saying we are collecting that and I can give some interim analysis. We're about $75 \%$ through the nonmortality data.

So in regards to your question about anticoagulation, the vast majority of patients that we follow at $\mathrm{CHOP}$ in childhood are anticoagulated with aspirin alone. In older adulthood, we tend to transition a lot of our patients to warfarin, but those would be at an age range of sort of outside of this study. So the vast majority of the patients in this study were on aspirin alone.

And we are collecting data on thromboembolic events. That's not completely analyzed yet and so we will have that but I can't give you an eloquent answer on that at this point.

Dr Sarris. Well, we look forward to listening to the update in the future.

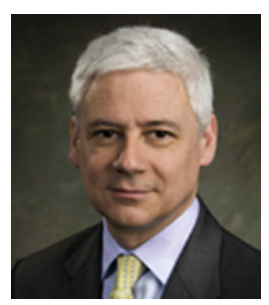

Dr C. Pizarro (Wilmington, Del). Beautiful job. Just a quick question. A few years ago, we looked at our own data in a few hundred patients and it seems that the patients who had prolonged effusions were patients who had issues related to recoarctation. Did you have an opportunity to look at the influence of recoarctation on the incidence of prolonged effusions and the effectiveness of balloon intervention to address this issue?

Dr Downing. Are you asking about recoarctation prior to the Fontan?

Dr Pizarro. Correct.

Dr Downing. That is not data that's directly linked to this data set, so I can't specifically correlate the patients who might have had that with the prolonged drainage, but that's an excellent question.

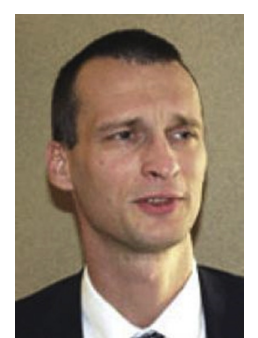

Dr d'Udekem (Victoria, Australia). It appears that ventricular dominance was not related to death in your study. Did you analyze heterotaxia? Was heterotaxia related to deaths, or did you look at it?

Dr Downing. So the question is: is heterotaxy syndrome related to death? And yes, we did analyze that. Approximately $8 \%$ of our patients had heterotaxy, and it was actually not found to be a significant predictor for early or late death, which was actually somewhat of a surprise to me. In fact, none of the patients who died early had heterotaxy syndrome, so we were unable to even include it in the model. It was a divide-by-zero phenomenon.

Dr C. Backer. I'm intrigued by the fact that you slowly appear to have transitioned from lateral tunnel to extracardiac Fontan. I want to ask this august audience for a quick show of hands: In the current era how many people are doing lateral tunnel Fontans as their primary Fontan strategy?

(Show of hands.)

Looks like about maybe 10 hands.

And how many people have used the extracardiac Fontan? (Show of hands.)

So it looks like it's about $90 \%$ extracardiac and $10 \%$ lateral tunnel.

You were using the fenestration in all your patients with excellent results. How many people in the audience are using fenestrations routinely?

(Show of hands.)

And how many are not?

(Show of hands.)

That looks to me like about a 50/50 split.

So should we be using fenestrations in everybody, yes or no?

Dr Downing. I can't answer that question. We do it on all of them.

Dr Backer. This was an excellent presentation, I congratulate you on outstanding results, and that was a very nice discussion. 
APPENDIX E1. Variables considered in risk factor analysis

- Demographic factors: sex, era of Fontan operation

- Pre-Fontan surgical factors: type of stage 1 palliation (Norwood vs nonNorwood), type of stage 2 palliation, age at stage 2 palliation, weight at stage 2 palliation.

- Anatomic and physiologic factors: heterotaxy syndrome, presence of common atrioventricular valve, morphology of systemic ventricle, hypoplastic left heart syndrome, pre-Fontan pulmonary artery pressure, ${ }^{*}$ pre-Fontan ventricular end-diastolic pressure.**

- Fontan surgical factors: type of Fontan operation, age at Fontan, weight at Fontan, presence of fenestration, use of modified ultrafiltration, cardiopulmonary bypass time, crossclamp time.

- Perioperative factors: duration of intensive care unit stay, duration of mechanical ventilation, duration of pleural drainage, duration of hospital stay.

*Catheterization parameters were incorporated into subset analyses only, as described in the text. APPENDIX E2. Supplementary data for survival analysis
(supplementary data for Figure 1)

\begin{tabular}{|c|c|c|}
\hline Time from Fontan, $y$ & Estimated survival ${ }^{*}$ & $\begin{array}{c}95 \% \text { confidence } \\
\text { interval }(\%)\end{array}$ \\
\hline \multicolumn{3}{|l|}{ Overall survival } \\
\hline $0.083(1 \mathrm{mo})$ & $97 \%$ & $95-98$ \\
\hline 1 & $94 \%$ & $92-95$ \\
\hline 5 & $92 \%$ & $90-94$ \\
\hline 10 & $90 \%$ & $88-92$ \\
\hline 15 & $85 \%$ & $82-88$ \\
\hline 20 & $74 \%$ & $67-80$ \\
\hline \multicolumn{3}{|c|}{ Cumulative hazard $\dagger$} \\
\hline \multicolumn{3}{|l|}{ Death } \\
\hline $0.083(1 \mathrm{~m})$ & $3 \%$ & $2-4$ \\
\hline 1 & $5 \%$ & $4-7$ \\
\hline 5 & $7 \%$ & $5-9$ \\
\hline 10 & $8 \%$ & $6-10$ \\
\hline 15 & $12 \%$ & $9-16$ \\
\hline 20 & $23 \%$ & $16-32$ \\
\hline \multicolumn{3}{|l|}{ Transplant } \\
\hline $0.083(1 \mathrm{~m})$ & $0 \%$ & $0-1$ \\
\hline 1 & $1 \%$ & $0-2$ \\
\hline 5 & $2 \%$ & $1-3$ \\
\hline 10 & $3 \%$ & $1-4$ \\
\hline 15 & $5 \%$ & $3-7$ \\
\hline 20 & $8 \%$ & $5-14$ \\
\hline \multicolumn{3}{|l|}{ Fontan takedown } \\
\hline $0.083(1 \mathrm{~m})$ & $0 \%$ & $0-2$ \\
\hline 1 & $1 \%$ & $1-2$ \\
\hline 5 & $1 \%$ & $1-2$ \\
\hline 10 & $1 \%$ & $1-2$ \\
\hline 15 & $1 \%$ & $1-2$ \\
\hline 20 & $1 \%$ & $1-2$ \\
\hline
\end{tabular}

*Kaplan-Meier survival function. †Nelson-Aalen cumulative hazard function.
APPENDIX E3. Supplementary data for Figure 2

\begin{tabular}{|c|c|c|}
\hline $\begin{array}{l}\text { Time from } \\
\text { Fontan, } y\end{array}$ & $\begin{array}{l}\text { Estimated } \\
\text { survival }^{*}\end{array}$ & $\begin{array}{c}95 \% \text { confidence } \\
\text { interval }(\%)\end{array}$ \\
\hline \multicolumn{3}{|c|}{ All patients (Figure 2, $A$ ) } \\
\hline \multicolumn{3}{|c|}{ Era 1 (1992-1996) } \\
\hline $0.083(1 \mathrm{mo})$ & $93 \%$ & $89-96$ \\
\hline 1 & $88 \%$ & $83-92$ \\
\hline 5 & $86 \%$ & $80-90$ \\
\hline 10 & $85 \%$ & $79-89$ \\
\hline 15 & $80 \%$ & $74-84$ \\
\hline 20 & $69 \%$ & $61-76$ \\
\hline \multicolumn{3}{|c|}{ Era 2 (1997-2002) } \\
\hline $0.083(1 \mathrm{mo})$ & $98 \%$ & $95-99$ \\
\hline 1 & $96 \%$ & $92-98$ \\
\hline 5 & $94 \%$ & $90-97$ \\
\hline 10 & $92 \%$ & $88-95$ \\
\hline 15 & $87 \%$ & $80-92$ \\
\hline \multicolumn{3}{|c|}{ Era 3 (2003-2009) } \\
\hline $0.083(1 \mathrm{mo})$ & $99 \%$ & $97-99$ \\
\hline 1 & $97 \%$ & 94-98 \\
\hline 5 & $95 \%$ & $92-97$ \\
\hline 9 & $94 \%$ & $89-96$ \\
\hline \multicolumn{3}{|c|}{ Conditional on survival to $1 \mathrm{y}$ (Figure $3, B$ ) } \\
\hline \multicolumn{3}{|c|}{ Era 1 (1992-1996) } \\
\hline 5 & $97 \%$ & $93-99$ \\
\hline 10 & $96 \%$ & $92-98$ \\
\hline 15 & $90 \%$ & $85-94$ \\
\hline 20 & $78 \%$ & $70-85$ \\
\hline \multicolumn{3}{|c|}{ Era $2(1997-2002)$} \\
\hline 5 & $98 \%$ & $95-99$ \\
\hline 10 & $96 \%$ & $92-98$ \\
\hline 15 & $91 \%$ & $84-95$ \\
\hline \multicolumn{3}{|c|}{ Era 3 (2003-2009) } \\
\hline 5 & $98 \%$ & $96-99$ \\
\hline 9 & $97 \%$ & $92-99$ \\
\hline
\end{tabular}

*Kaplan-Meier survival function 

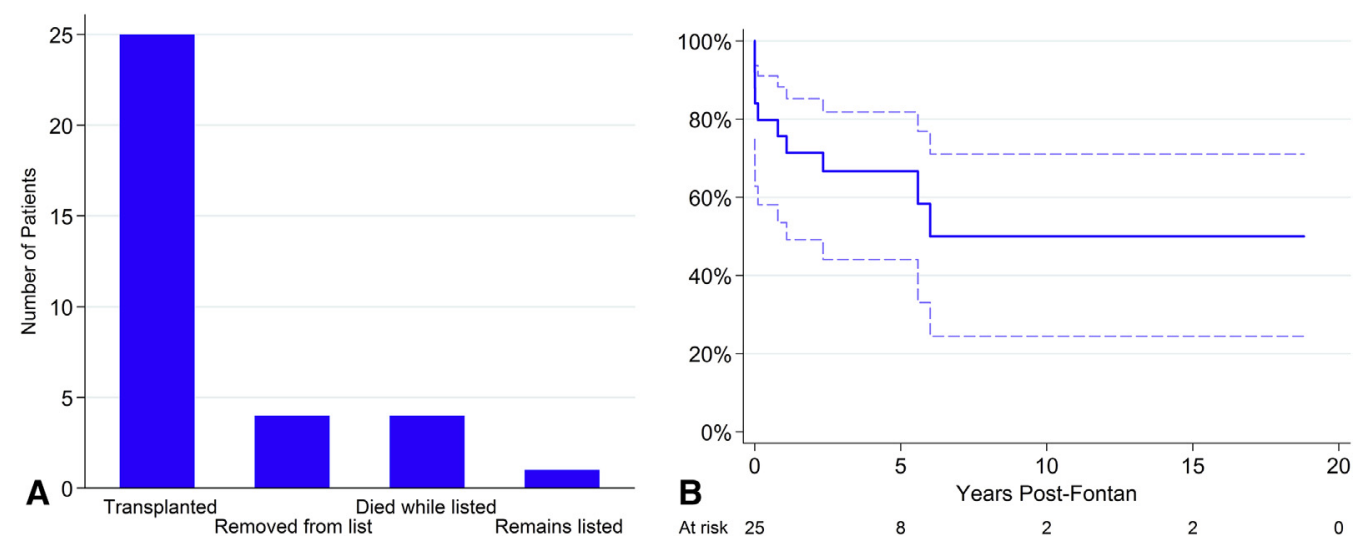

FIGURE E1. Transplantation after Fontan operation. A, Outcome of transplant listing. B, Kaplan-Meier estimate for survival after heart transplantation. Dashed lines represent $95 \%$ confidence intervals of the survival function.

TABLE E1. Comparison of population characteristics and survival outcomes in recent Fontan follow-up studies

\begin{tabular}{|c|c|c|c|c|c|c|c|c|}
\hline Study & Cohort years & $\mathbf{n}$ & $\begin{array}{c}\text { Median } \\
\text { follow-up, } y\end{array}$ & $\begin{array}{c}\text { Follow-up } \\
\text { rate }\end{array}$ & Fontan type & $\begin{array}{c}\text { Systemic } \\
\text { RV }\end{array}$ & HLHS & Survival \\
\hline CHOP cohort & 1992-2009 & 773 & 9 & $99 \%$ & $\begin{array}{l}0 \% \text { AP } \\
53 \% \text { LT } \\
47 \% \text { EC }\end{array}$ & $67 \%$ & $50 \%$ & $\begin{array}{l}\text { - } 83 \% \text { overall survival at } \\
20 \mathrm{y} \\
\text { - } 79 \% \text { transplant/takedown- } \\
\text { free survival at } 20 \mathrm{y}\end{array}$ \\
\hline Pundi et al, ${ }^{12} 2015$ & $1973-2012$ & 1052 & 15 & $68 \%$ & $\begin{array}{l}59 \% \text { AP } \\
25 \% \text { LT } \\
11 \% \text { EC }\end{array}$ & $<45 \%$ & $2 \%$ & $\begin{array}{l}\text { - } 61 \% \text { overall survival at } \\
20 \mathrm{y} \\
\text { - } 59 \% \text { transplant-free } \\
\text { survival at } 20 \mathrm{y}\end{array}$ \\
\hline Nakano et al, ${ }^{14} 2015$ & 1994-2014 & 500 & 7 & NR & $\begin{array}{l}0 \% \text { AP } \\
0 \% \text { LT } \\
100 \% \text { EC }\end{array}$ & NR & $15 \%$ & $\begin{array}{l}\text { - } 93 \% \text { overall survival at } \\
15 \mathrm{y} \\
\text { - No transplants performed }\end{array}$ \\
\hline d'Udekem et al, ${ }^{9} 2014$ & $1975-2010$ & 1006 & NR & $96 \%$ & $\begin{array}{l}20 \% \text { AP } \\
27 \% \text { LT } \\
53 \% \text { EC }\end{array}$ & $31 \%$ & $9 \%$ & $\begin{array}{l}\text { - } 90 \% \text { overall survival at } \\
20 \text { y for perioperative } \\
\text { survivors } \\
\text { - } 2 \% \text { of patients underwent } \\
\text { heart transplantation }\end{array}$ \\
\hline Dabal et al, ${ }^{13} 2014$ & $1988-2011$ & 207 & 5 & $89 \%$ & $\begin{array}{l}0 \% \text { AP } \\
29 \% \text { LT } \\
71 \% \text { EC }\end{array}$ & NR & $9 \%$ & $\begin{array}{l}\text { - } 77 \% \text { overall survival at } \\
20 \mathrm{y} \\
\text { - Only } 1 \text { patient underwent } \\
\text { heart transplantation }\end{array}$ \\
\hline Khairy et al, ${ }^{11} 2008$ & 1973-2008 & 261 & 12 & $<50 \%$ & $\begin{array}{l}62 \% \text { AP } \\
37 \% \text { LT } \\
1 \% \text { EC }\end{array}$ & $30 \%$ & $5 \%$ & $\begin{array}{l}\text { - } 68 \% \text { transplant-free } \\
\text { survival at } 20 \mathrm{y}\end{array}$ \\
\hline Hirsch et al, ${ }^{10} 2008$ & $1992-2007$ & 636 & 4 & NR & $\begin{array}{l}0 \% \mathrm{AP} \\
92 \% \mathrm{LT} \\
8 \% \mathrm{EC}\end{array}$ & $64 \%$ & $52 \%$ & $\begin{array}{l}\text { - } 91 \% \text { overall survival at } \\
14 \text { y for perioperative } \\
\text { survivors }\end{array}$ \\
\hline
\end{tabular}

$R V$, Right ventricle; $H L H S$, hypoplastic left heart syndrome; $C H O P$, Children's Hospital of Philadelphia; $A P$, atriopulmonary; $L T$, lateral tunnel; $E C$, extracardiac conduit; $N R$, not reported. 